\title{
Transition from molecular diffusion to natural circulation mode air-ingress in high temperature helium loop
}

\author{
Daniel Gould ${ }^{\mathrm{a}}$, Daniel Franken ${ }^{\mathrm{a}}$, Hitesh Bindra ${ }^{\mathrm{a}, *}$, Masahiro Kawaji ${ }^{\mathrm{b}}$ \\ ${ }^{a}$ Department of Mechanical and Nuclear Engineering, Kansas State University, Manhattan, KS, 66506 \\ ${ }^{b}$ Department of Mechanical Engineering, City College of New York, City University of New York, New York, NY 10031
}

\begin{abstract}
High Temperature Gas-cooled Reactors (HTGRs) have significantly robust passive heat removal capabilities owing largely to conduction and radiation heat transfer through graphite-fuel matrix and reactor vessel wall respectively. However, these capabilities may be significantly impacted if air was to replace Helium in the high temperature graphite under accident scenarios. In case of break in the coolant system high pressure Helium will escape into the reactor cavity leading to depressurization of the reactor. This will allow air from reactor cavity to enter the plenum or core of HTGRs via different mechanisms - diffusion, gravity currents, or natural circulation. Experimental studies were conducted in a geometrically scaled set-up with a shape of small English letter 'h', to depict the role of upper plenum in this process. Main focus of these studies was to understand and observe the transition time from diffusion to natural circulation. Thermal camera is used to identify this transition and flow transducer is used to measure the flow rates. The experimental results on incipience time of natural convection after a chamber pre-filled with Helium is opened to atmosphere are qualitatively similar to observations reported in literature using 'inverse U' shaped experimental setup, but also show distinct quantitative effect of extended leg on the transition times. Prior to onset of natural circulation $(\mathrm{ONC})$, molecular diffusion plays the significant role in air-ingress. However, at higher temperatures convection currents may be influencing air ingress and in-turn ONC times.
\end{abstract}

Keywords: HTGRs, Air ingress, Diffusion, Natural circulation

\section{Nomenclature}

$\Omega_{D} \quad$ Temperature-dependent collision integral

$\sigma_{A-B}$ Average Collision diameter $(\AA)$

$\tau \quad$ Diffusion time constant (s)

$D \quad$ Diffusivity $\left(\mathrm{cm}^{2} / \mathrm{s}\right)$

$L \quad$ Length $(\mathrm{cm})$

$M \quad$ Molar mass $(\mathrm{g} / \mathrm{mol})$

$P \quad$ Pressure (atm)

$T \quad$ Temperature (K)

$t \quad$ ONC time (s)

y Mole fraction

${ }^{*}$ Corresponding author

Email address: hbindra@ksu.edu (Hitesh Bindra)

\section{Introduction}

The next generation of nuclear power plants, such as HTGRs, have passive safety design features during offnormal operation, however it is unproven whether their safety systems will perform as per design requirements. The optimal approach to gain this understanding is to computationally model relevant phenomena using either system level or detailed 3D multiphysics codes, and then conduct HTGR related separate effects experiments using scaled models. These models can provide validation data and complement computational efforts to identify critical issues related to passive safety design. Several Phenomena Identification and Ranking Tables (PIRT) for HTGRs show that under normal steady-state, transient, and accident scenarios, the key phenomena leading to localized hot spots in the reactor core include air ingress, watersteam ingress, natural convection, degraded heat transfer in coolant channels, flow laminarization, effects of bypass flow, and non-uniform heat generation across the core $[1,2,3,4]$. Some of these phenomena have been understood in-depth in recent years but air-ingress is one of the less understood topics till now.

A common feature of HTGRs with a passive safety design is that under certain accident conditions the decay heat is dissipated passively from the core by radiation- 


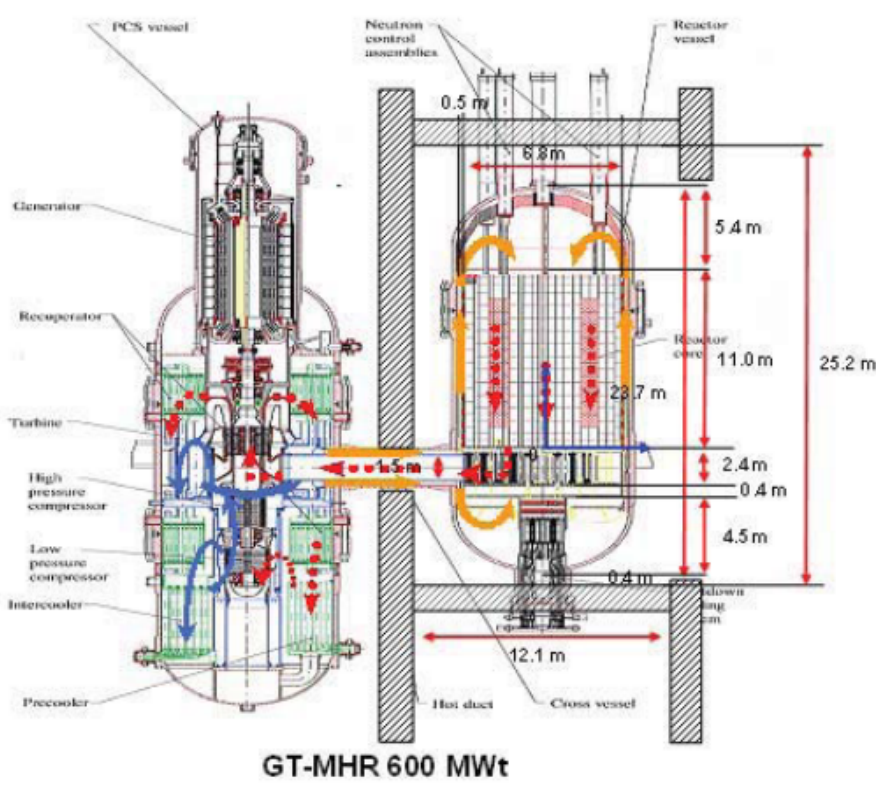

(a) GT-MHR [5]

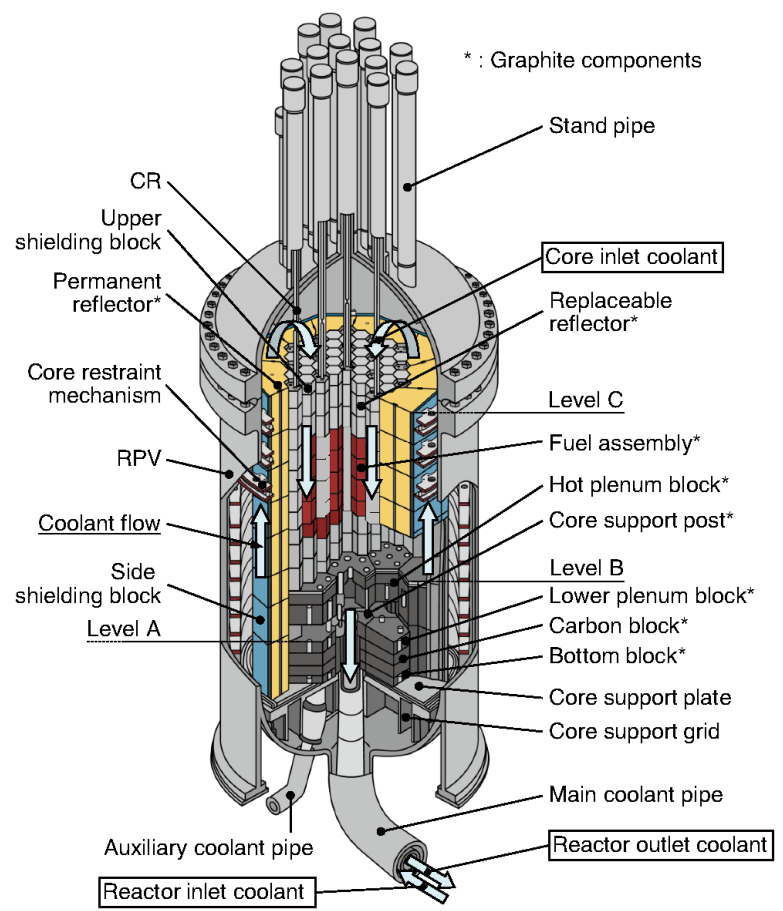

(b) HTTR [6]

Figure 1: Two gas-cooled graphite moderated reactor designs: GT-MHR and HTTR

conduction-convection heat transport to the surrounding environment. Conduction and radiation heat transfer are expected to provide long-term heat removal. However, during a Depressurized Loss of Forced Coolant (DLOFC) accident, a break in the coolant system will allow air ingress into the high temperature reactor and can lead to graphite oxidation, which will negatively impact the core thermal behavior. Air ingress in the HTGR plena and core regions is a complex process and highly dependent upon the specific geometry of both the reactor and the break. While there have been several analytical or computational studies to estimate air ingress rates in HTGRs, most previous studies have been based on hypothetical scenarios of break-size and orientation.

The High Temperature Test Facility (HTTF) [7] at Oregon Sate University is a $1 / 3$ scale model of Gas turbine Modular Helium Reactor (GT-MHR) - the American HTGR design - and will be used in the future to perform airingress experimental studies[8]. Additionally, a 1/8th scaled model for lower plenum has been designed at Ohio State University to study air ingress experiments $[9,10]$.

One of the goals of the proposed experiments in each of these facilities is to investigate mechanisms for air ingress from the containment or reactor cavity into the lower plenum and core after a double-guillotine break of the main inletoutlet co-axial header of GT-MHRs. There are three different possible modes of air-ingress: molecular diffusion due to a concentration gradient of helium-air, convective transport of air, and natural convection due to a thermally driven upward draft in the core. If the dominating mecha- nism is molecular diffusion, the rate of air-ingress is quite slow, whereas if the driving mode is convective transport, air circulation can start within few minutes. The analytical or computational studies performed on these hypothetical accidents in GT-MHRs suggest that due to gravity currents (lock-exchange) the convective air-ingress mode is reached instantaneously $[5,12]$. This air flow into the lower plenum and core with high temperature graphite can lead to adverse consequences such as oxidation of graphite and can negatively impact the passive heat removal capabilities of the reactor. Therefore, it is highly desired to know accurately when this natural convection would begin. It has been suggested by Oh and others[11, 13, 14] that the sequence of events during an air ingress accident involve : (1) depressurization, (2) density-driven stratified flow, (3) diffusion into the reactor core, and (4) global natural circulation (Fig. 2). The potential formation and effect of stratified flow is highly dependent on a given reactor design. The nature of this stratified flow after depressurization determines the initiation time and rate of air ingress into the reactor vessel. At some point after the development of the stratification regime and the filling of the lower plenum with air global natural circulation will begin. However, there are conflicting reports in the literature on the onset of natural convection time.

According to simulation results obtained by Oh et al.[5] using a CFD code, FLUENT, showed that the onset of natural convection time is expected within 100 secs of depressurization. However, simulations performed using the previously validated, 2D Gamma code[15, 16] reveal that 


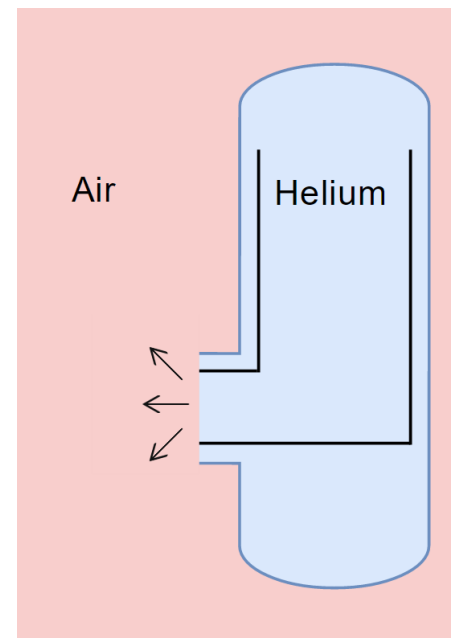

(a) Depressurization

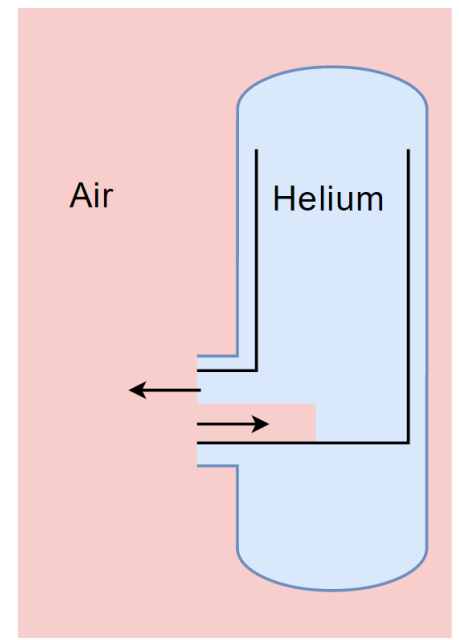

(b) Stratified Flow

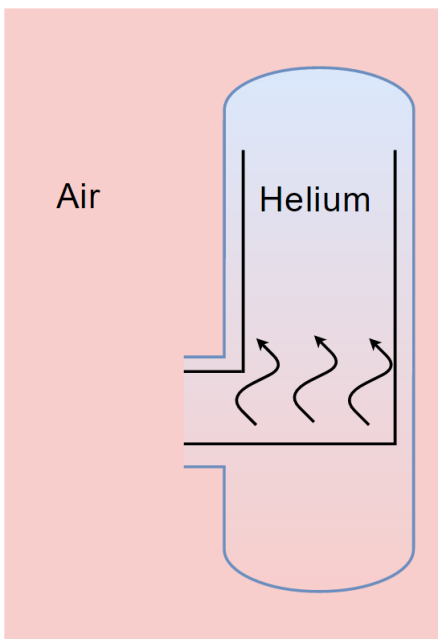

(c) Diffusion

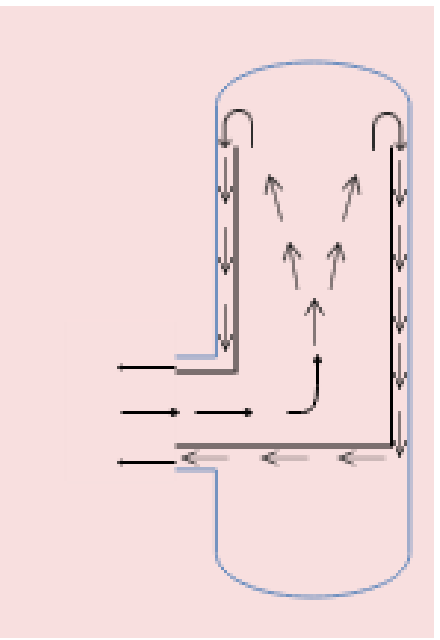

(d) Natural Convection

Figure 2: Air ingress scenario with helium-air stratification and diffusion[11]

the onset of natural circulation within an HTGR is anticipated to occur several hours - rather than several seconds - after the depressurization event. Unfortunately, there is currently a very limited amount of experimental data in the established literature that can be used to understand this transition from diffusion to natural circulation and validate numerical models. In a separate-effects experimental study on isothermal air ingress through horizontal ports in a helium filled scaled-vessel[17], it was found that it would take several minutes to fill the entire test chamber - a result that differs from the numerical predictions by $\mathrm{Oh}$ et al. [5, 12].

The predictive modeling of this process is quite challenging because the CFD codes don't have appropriate models for properties such as molecular diffusion in binary mixtures. The thermophysical properties such as thermal conductivity, viscosity and specific heat capacity of helium-air mixtures strongly vary with the air concentration or with the presence of any heavier gas [18, 19], and are difficult to model. At intermediate concentrations, the Prandtl number of these binary mixtures reduces to values well below those of common gasses. This reduction increases the uncertainty in the applicability of the conventional heat transfer correlations and turbulence models. Taylor et al.[20] showed that some of the most popular correlations over-predicted convective heat transfer for binary gas mixtures in forced convection. The uncertainty would be even greater at low Reynolds numbers and for natural convection flows. Therefore, despite the large volume of work that has been done on this subject, the computational models may require further improvements before they can be reliably used for design basis studies.

The underlying physics for the transition from molecular diffusion to natural circulation is highly dependent upon the concentration of Helium within the core. If the overall Helium concentration is high, the difference in average fluid density between the hot core region and gap region (the space between core barrel and vessel wall) is insufficient to initiate natural circulation. Only when the air concentration in the core reaches a certain value will the density difference between the hot and cold legs be sufficient for the natural circulation of cavity air through the core to begin. Most of the experimental high temperature studies on understanding this transition were conducted by JAERI[21, 22, 23] with an 'inverted U' shaped experimental facility based on the HTTR. Although there are coolant inlet-outlet process design differences between HTTR and GT-MHR, the central physics of depressurization and air-ingress are expected to be governed by similar fundamental mechanisms. These experimental results were also later modeled using the CFD code, FLUENT, by Zhai et al. [24, 25]. While the experimental studies from JAERI do indeed help in understanding the transition, the 'inverted U' design does not take into account the possible effect of the upper plenum on molecular diffusion and air ingress rate.

First, as one can see in Figure 1a, the upper plenum of the proposed GT-MHR reactor design resides directly above the entrance to the coolant inlet channel. After a break, the helium contained within the upper plenum of the reactor will diffuse downward. This process will have the effect of slowing the rise in air concentration in the upper part of the reactor and thus potentially changing the time at which ONC would occur. Thus, a new 'h' shaped experimental facility designed to represent the effect of unmixed helium in the upper plenum was developed and used for the experimental studies presented in this work.

The experimental studies presented here have two goals: a) Experimentally study diffusion to natural circulation transition process with air-ingress into the helium filled chamber. b) Examine the effect of upper unheated heliumfilled plenum or chamber on the ONC. The remainder of this paper is organized into three sections: experimental setup design and procedure, results and analysis, and con- 
clusions.

\section{Experimental Setup and Procedure}

To experimentally determine the effect that helium diffusion from the upper plenum might have on the ONC time, a new experimental setup was designed, based on the 'inverted U' design of experimental setups from literature $[21,22,23]$. The ' $h$ ' shaped experimental setup developed for this study is made of quartz tubing welded together as shown in Figure 3a. Tube diameters for all the legs in the set-up were selected to be similar to those in the inverted U' shaped setup used in previous studies [23]. While visually very similar to setups developed by JAERI, such as the example shown in Figure 3b, the additional vertical tube seen on the upper left side of the apparatus provides several advantages.

First, the extended upper leg of the "h" allows a mass of helium to be present above the 'inverted U' flow loop, modeling the effect that the helium within the upper plenum of the GT-MHR would have on the time duration experienced from the initial coolant pipe rupture and depressurization until ONC. Secondly, the extended upper leg allows for the insertion of instrumentation and test specimens into the left leg of the assembly. In future studies, this upper leg and the flange will be used to create a scenario of 'control drive nozzle break' postulated accident listed as one of the tests in the matrix provided by Schulz et al. [7].

As presented in Figure 3a, the three legs in the apparatus were made of $46 \mathrm{~mm}$ ID by $50 \mathrm{~mm}$ OD quartz tube. It should be noted here that 'inverted U' facility at JAERI had ID of all the tube legs about $40.5 \mathrm{~mm}$, but this small variation in the tube area is not expected to play any major in the governing physics. The length of each legs was designed based on the geometric scaling with GT-MHR, i.e., the ratio of upper unheated leg to the heated leg was designed to be 1.5 which is close to the ratio of height of upper plenum to core in the GT-MHR. The heights of GTMHR core and upper plenum regions were obtained from literature $[26,27]$. Low thermal conductivity of quartz eliminated the need for a cooling system on the cold leg of the assembly. Radiative tube furnaces were used to heat the lower portion of the left leg of the ' $h$ ' shaped test section.

The manufactured quartz ' $h$ ' is originally open to atmosphere at each of its three ends. Before initiating the experiments, all three openings were sealed using KF50 flange connections. For this ONC study, the two lower fittings were opened to simulate a sudden double guillotine break of the main coolant pipe. The third, upper opening remained sealed throughout the experiments performed for this work.

A FLIR A655sc LWIR camera was used to monitor the temperature of the setup before and during experiments. Before each experimental run, the LWIR camera was used to determine when the apparatus had reached steady state conditions. In Figure 3a, the portion of the apparatus that can be directly observed with the LWIR camera is marked with a red dashed box.

During each experimental run, the LWIR camera was also used to detect the precise moment that the ONC occurred. This was done by continuously monitoring the values of the pixels making up the upper right corner of the quartz assembly. The approximate location of these pixels is also shown in Figure 3a. It was found that, after ONC, the upper-right corner of the quartz 'h' would be the first area to experience any measurable temperature change as shown in Figure 4. By tracking the average value of 40 pixels in this area denoted as "Target Pixels" in Figure 3a), ONC could be identified within seconds of it occurring. For example, the histories of the average temperatures in the targeted pixels plotted in Figure 5 clearly show the ONC during the experimental runs performed with a hot leg temperature of $375^{\circ} \mathrm{C}$.

The measurement of ONC by the LWIR camera was also confirmed using a TSI 8475 flow transducer that was placed directly under the lower left opening of the assembly. Both of these measurement methods generally agreed on the ONC time to within 10 seconds of one another.

The following steps were followed for each run of the ONC experiments.

1. Air is evacuated from the chamber with the help of vacuum pump and a rough vacuum is achieved.

2. Helium is filled into the chamber until pressure inside the chamber is almost equal to atmospheric pressure.

3 . The left leg of the chamber is heated to the desired temperature.

4. Any excess helium is removed to ensure chamber pressure equal to atmospheric pressure.

5 . Both of the lower ends of the chamber are opened simultaneously.

6. The flow measurement probe is moved into place under the left hand side chamber opening.

7. Chamber wall temperature and system flow rate are monitored to determine ONC.

\section{Results and Analysis}

As described in the previous section, $\mathrm{ONC}$ was detected when the instantaneous average value of the pixels identified in Figure 3a underwent a sudden, steep change. This "steep change" can be seen in Figure 5. The time histories of the three test runs at the same hot leg temperature also show the consistency of the experimental results.

The ONC times experienced by the setup were measured for five different hot-leg temperatures. For each tested hot-leg temperature, several experimental runs were performed both to ensure experimental repeatability and to obtain data with uncertainties. The particular hotleg temperatures used in this work were picked to closely match the hot-leg temperatures used in previous work reported by JAERI[23]. Experimentally measured ONC times from both the present work and JAERI's previous study[23] 


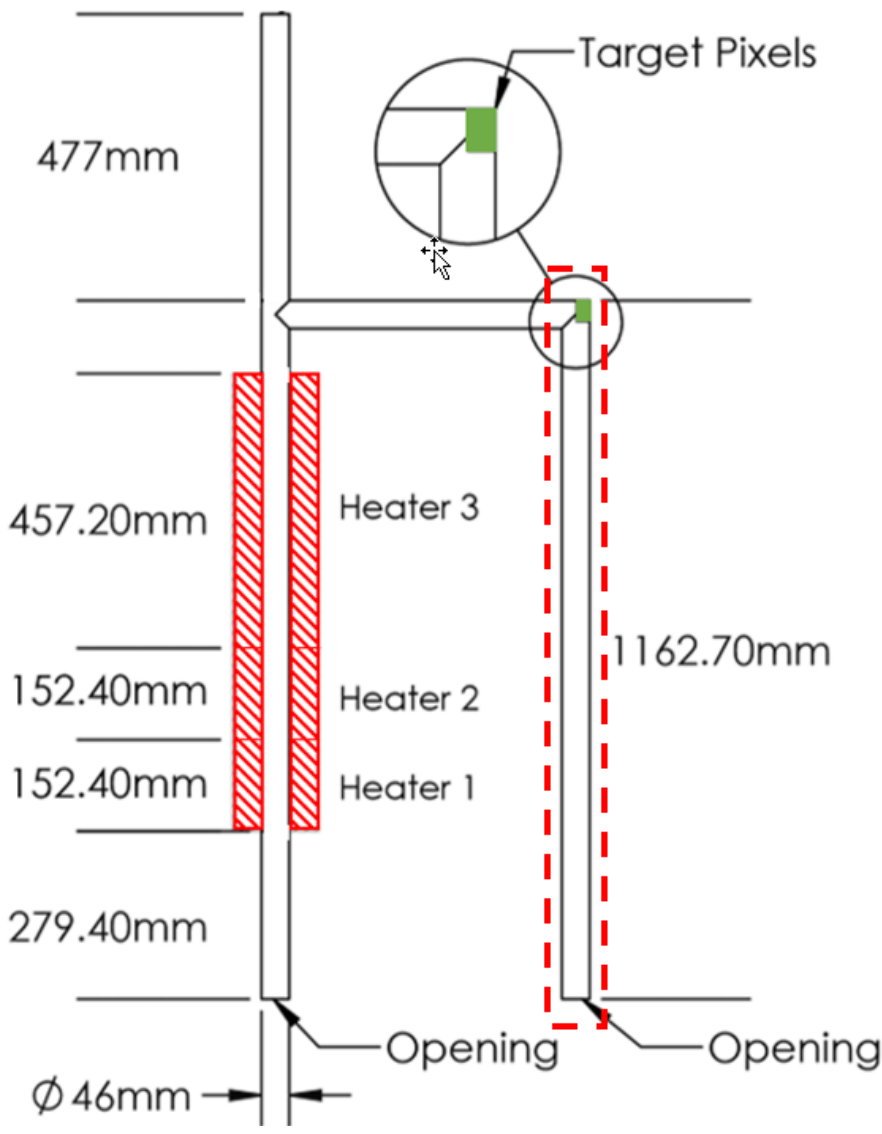

(a) Diagram of ' $h$ ' shaped experimental apparatus developed for this study. Dashed red box highlights the observation window for ONC detection.

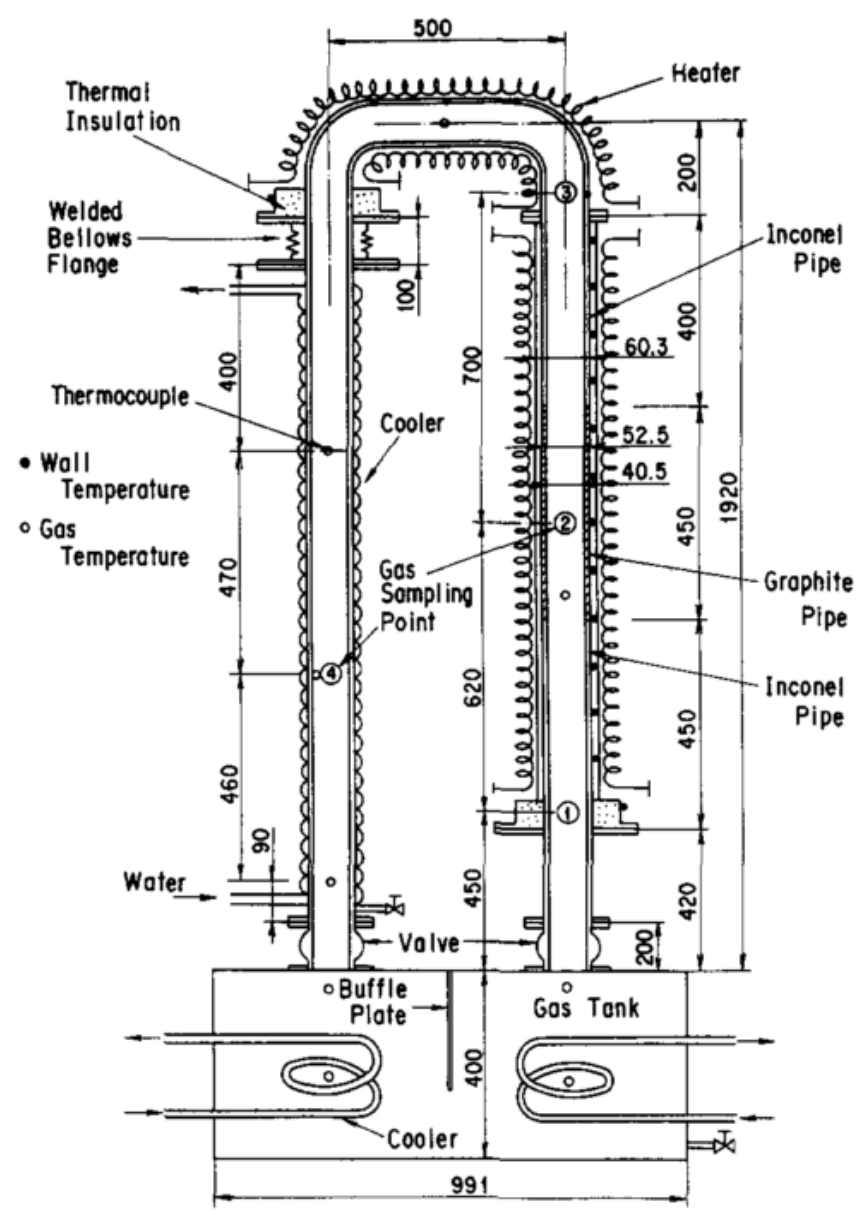

(b) Diagram of 'inverse U' shaped experimental apparatus from JAERI. shown dimensions in $\mathrm{mm}$. [23]

Figure 3: Experimental Setups for studying transition or Onset to Natural Circulation

are plotted in Figure 6. Results from both studies show that as the temperature of the hot-leg is increased, the ONC time is reduced. This behavior is expected and can be explained by increase in molecular diffusion and increased density difference driven convection currents with increase in temperature of the hot-leg.

\subsection{Calculation of Diffusion Coefficient and Experimental Time Constant}

In order for valid comparisons to be made between the results of the present work with those of JAERI, several small differences between the two setups had to be accounted for (see Table 1). First, and most significantly, while the horizontal tube connecting the two long legs of both experimental setups are identical in length, the vertical legs used in the 'inverted U' setup are longer than the lower portions - that is, the portions of the legs below the horizontal connecting tube - of the vertical legs that were used in the experiments described here. Additionally, slightly different fractions of the hot legs were actually heated to the specified temperature. Additionally, some of the most relevant or comparable results from
JAERI [21, 22], were obtained using helium and nitrogen rather than helium and air.

Therefore, to take into account these variations, the time constant $\tau$ was defined to better understand and scale the processes in the two different facilities. This time constant was derived based on the assumption that, prior to ONC, molecular diffusion is the dominating mechanism for increasing the air concentration within the test chambers.

When calculating $\tau$, the hot vertical leg - i.e. the lower portion of the left vertical leg in the current work, (see Figure 3a) and the right vertical leg in the previous work by JAERI (see Figure 3b) - were, for analytical purposes, split into a number of segments. Each segment was defined in such a way as to approximate that, under steady-state conditions prior to ONC, the temperature - and therefore diffusion coefficient - of each segment was constant over its length. This constraint resulted in dividing the hot leg of the JAERI setup into two segments. The hot leg of ' $h$ ' shaped setup, developed and used in this present study, was divided into three segments.

The time constant of the entire hot leg was then defined as the sum of the time constants of the individual segments 


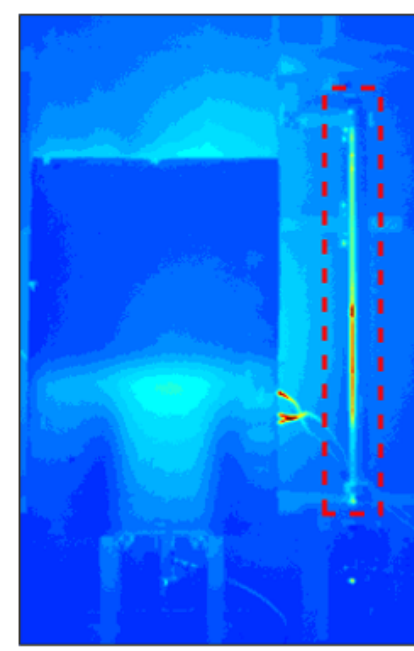

30 seconds before $\mathrm{ONC}$

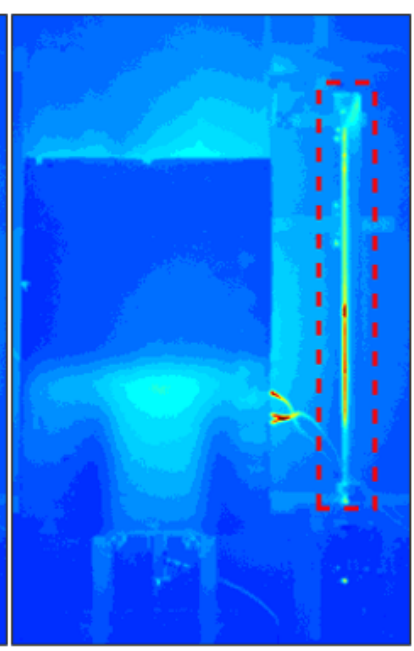

At ONC

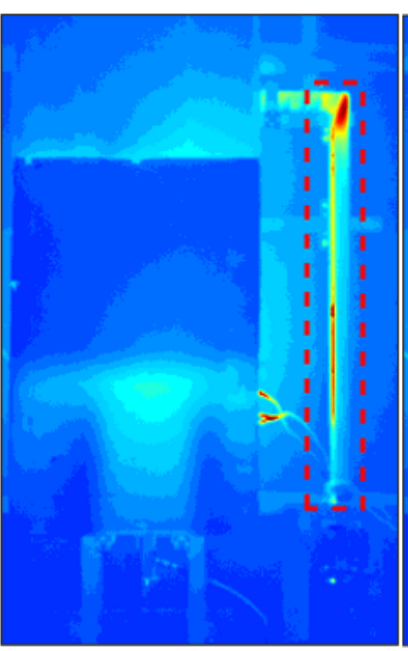

30 seconds after $\mathrm{ONC}$

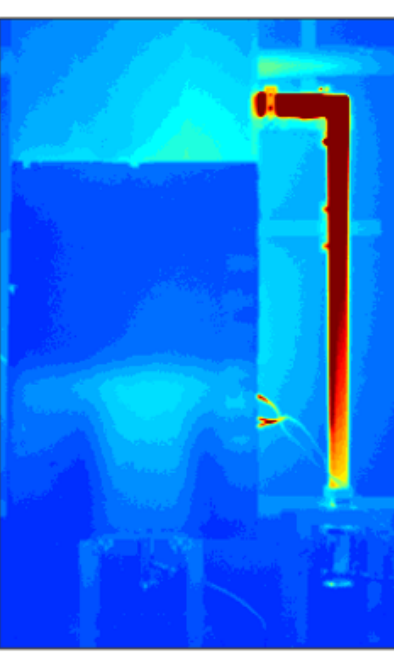

1206 seconds after $\mathrm{ONC}$

Figure 4: (Color Online) Images from FLIR camera before and after ONC. Observation window is identified by dashed red box.

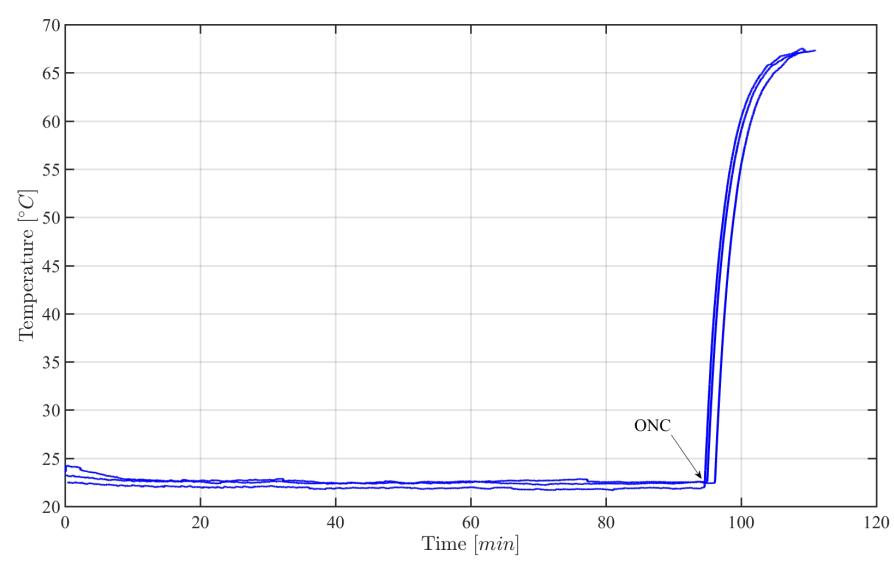

Figure 5: Average temperatures of target pixels

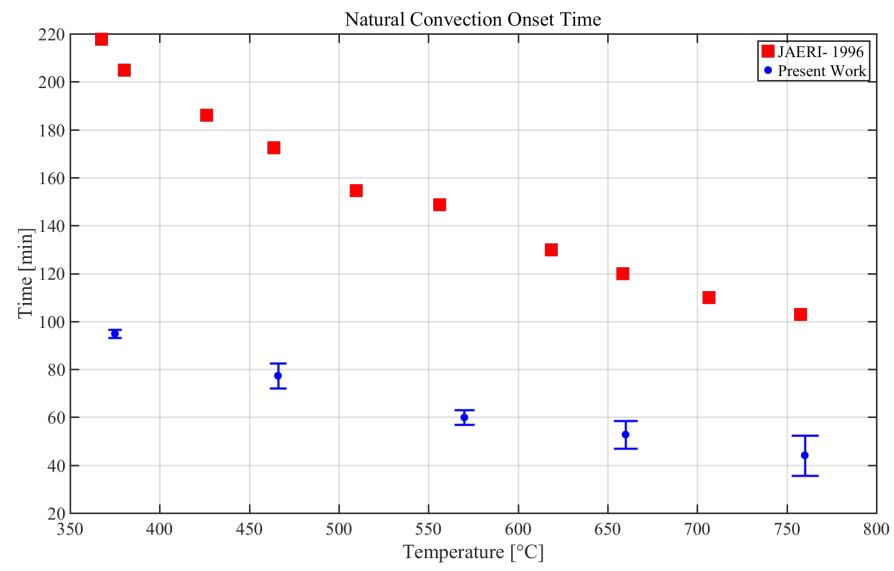

Figure 6: ONC time $(t)$ vs hot leg Temperature

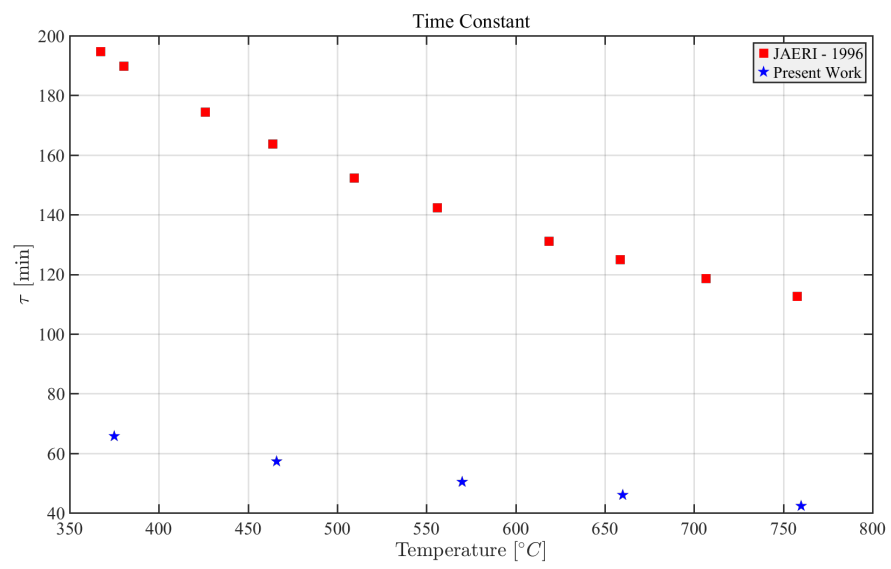

Figure 7: Diffusion time constant $(\tau)$ vs hot leg Temperature

within the analyzed leg. In Equation 3.1.1, $L_{j}$ is defined as the length of segment $j$ and $D_{j}$ as the diffusion coefficient in segment $j$.

$$
\tau=\sum_{j}\left[\frac{L_{j}^{2}}{D_{j}}\right]
$$

Equation 3.1.2 is used to calculate the diffusion coefficient for gas pairs $\left(D_{i}\right)$ of non-polar, non-reacting molecules [28] within a segment of the hot leg. Subscript $i$ denotes a particular gas pair such as Helium-Nitrogen. In case of Helium-Air, the diffusion coefficient was modeled with Helium-Nitrogen and Helium-Oxygen pairs. Wilke's approximation (Equation 3.1.3) was used to calculate the overall diffusion coefficient of helium into air $\left(D_{j}\right)$ from the diffusion coefficients of binary mixtures of its major 


\begin{tabular}{|c|c|c|}
\hline & Present Work & JAERI -1996[23] \\
\hline Leg Length [m] & 1.216 & 1.92 \\
\hline Heated Length [m] & 0.82 & 1.50 \\
\hline Interior Diameter [mm] & 46 & 40.5 \\
\hline Exterior Fluid & Air & $\mathrm{N}_{2}$ \\
\hline
\end{tabular}

Table 1: Experimental Setup Comparison

components [29].

$$
\begin{gathered}
D_{i}=\frac{.001858 T^{3 / 2}\left[\frac{1}{M_{A}}+\frac{1}{M_{B}}\right]^{1 / 2}}{P \sigma_{A-B}^{2} \Omega_{D}} \\
D_{j}=\left[\sum_{i} \frac{y_{i}}{D_{i}}\right]^{-1}
\end{gathered}
$$

In Figure 7, the values of $\tau$ calculated for the experimental conditions reported by JAERI [23] and the present study are plotted as a function of the temperature of the heated segment of the hot leg. The large variation in tau values as a function of temperature is expected as higher temperature leads to higher diffusion coefficient which implies the diffusion process is expected to be faster. The differences in the $\tau$ values for the two facilities is attributed to the differences in the length of the heated segments which strongly govern the diffusion process.

\subsection{Effect of Extended Leg}

The effect of extended leg on the ONC transition phenomenon is illustrated by the ratio of $\frac{\tau}{t}$ as calculated for each specific test temperature. This ratio is plotted in Figure 8. It can be clearly seen from the plots that for all hotleg temperatures tested, the ratio of $\frac{\tau}{t}$ calculated using the data generated in this work is lower than that calculated using the data from equivalent temperatures reported by JAERI[23]. This observation can be explained by the extra helium in the upper, extended portion of the left leg in the present setup. During the experiment, the helium initially present in the portion of the left leg above the horizontal cross diffuses downward into the lower portion of the apparatus - reducing the average air concentration in the lower leg and thus delaying ONC.

In both studies, the value of the ratio $\frac{\tau}{t}$ is directly proportional to the temperature. This behavior is due to the reduced dominance of molecular diffusion as the cause of increasing air concentration at higher temperatures. At higher temperatures, intra-leg natural convection also begins to play a role as predicted in the literature [21, 22]. It should be noted that although the value of the ratio $\frac{\tau}{t}$ seen in the present work is uniformly lower than than respective values generated from the JAERI experiments, the difference between the two respective ratios is not constant for all tested temperatures. Rather, the magnitude of the overall difference between the respective ratios plotted in Figure 8 appears to decrease with the hot leg temperature. This result can be partly attributed to 'natural

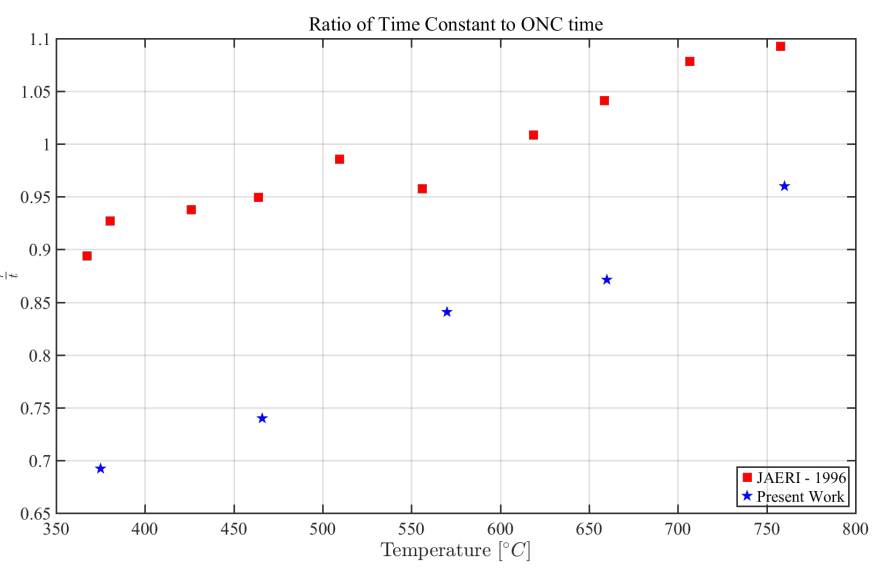

Figure 8: Ratio $\left(\frac{\tau}{\mathrm{t}}\right)$ vs hot leg Temperature

convection' [21] that occurs within each leg of the experimental apparatus before ONC. As the temperature of the hot leg will be directly proportional to the flow rate of the intra-leg convection currents, at higher temperatures these currents will be much more effective at introducing air into the hot leg of the setup. Correspondingly, the relative importance of diffusion in determining the air concentration within the hot leg will decrease as the temperature of the hot leg is increased. Thus, at higher temperatures the relative effect of the downward-diffusing helium on the ONC time decreases and the ratio of $\frac{\tau}{t}$ for the ' $h$ ' shaped experimental setup will approach the respective values obtained from the 'inverted U' shaped apparatus.

\subsection{Flow Velocity}

A flow transducer, described in experimental section, was placed under the lower opening of the left leg of the "h" shaped apparatus to provide corroboration of the ONC times identified by the LWIR camera. This flow instrument additionally helped in obtaining measurements of the average flow velocities at the tube entrance post-ONC. Due to both the extremely low flow rates and the close proximity of the heater to the flow transducer, flow rate measurements were associated with a high degree of uncertainties and were not sufficient to obtain a meaningful correlation between flow rates and the hot leg temperature. However, the flow velocity measurements that were obtained do agree very well with the approximate $0.2 \mathrm{~m} / \mathrm{s}$ value reported in earlier reports [22]. The obtained velocity measurements are plotted in Figure 9 with error bars showing $\pm 2 \mathrm{SD}$ of the measured values for each hot leg temperature. The accuracy level of the velocity probe was 
not sufficient to measure velocities prior to $\mathrm{ONC}$ or to quantify the role of intra-leg natural convection currents an unsurprising fact given that these currents are expected to be on the order of $1 \mathrm{E}-6 \mathrm{~m} / \mathrm{s}$ to $1 \mathrm{E}-4 \mathrm{~m} / \mathrm{s}$.

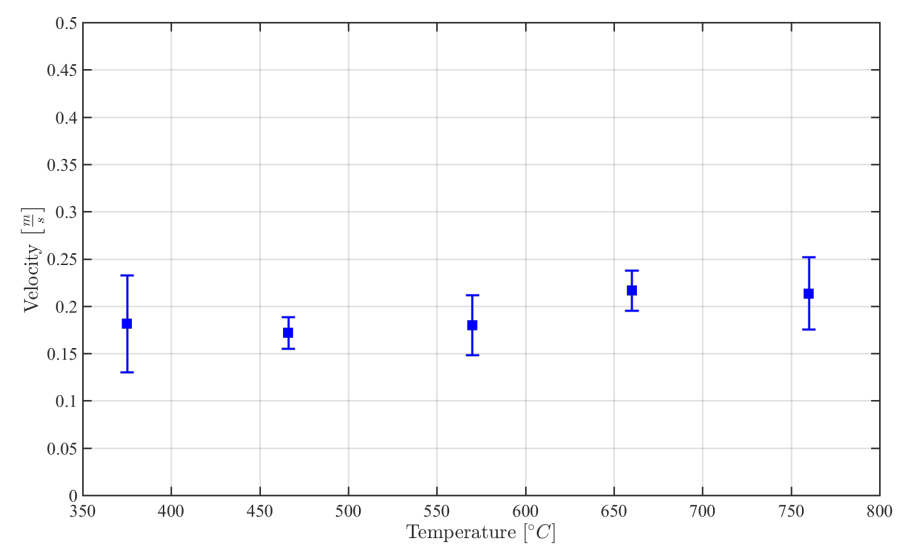

Figure 9: Flow velocity at hot leg inlet after ONC

\section{Conclusions}

Air-ingress after depressurization under inlet-outlet duct break is one of significantly important postulated scenarios under safety analysis of HTGRs. Previous experimental tests conducted at JAERI used 'inverse U' shaped setup to study transition from molecular diffusion to natural circulation. A new 'h' shaped setup was designed and developed in this study to understand the effect of upper unheated leg. In contrast to previous non-oxidizing studies, where Nitrogen was used as the gas present in external cavity, the present study was conducted with ambient air. Although both experimental studies have consistently shown that high temperature leads to earlier ONC, there were some clear differences in quantitative comparisons. Ratio of the diffusion time constant to ONC time, $\frac{\tau}{t}$, for the current study is found to be consistently lower than previous reports for the same corresponding test temperatures. This behavior can be attributed to the presence of this extended leg which increases the ONC time as it acts as an additional source of helium reservoir which leads to downward diffusion of helium.

As the hot leg test temperature was increased the ratio $\frac{\tau}{t}$ increased because of the increased role of natural convection currents. The experimental data on ONC times reported here will be useful for understanding and validating computer models. In the future, graphite test blocks will be placed in the high temperature helium tube to understand the effect of gaseous products from graphite oxidation on ONC behavior. Next steps will also involve the effect of opening or break orientation, such as horizontal opening and the break or leak at the top end of hot leg, on the ONC times.

\section{Acknowledgments}

The work presented was supported in part by the U.S. Department of Energy, Office of Nuclear Energy, under Award Number DE-NE0008412. The first and second authors thankfully acknowledge the support from Nuclear Regulatory Commission (NRC) fellowship and scholarship programs respectively.

\section{References}

[1] W. J. Lee, T. Y. Wei, R. R. Schultz, Generation of a preliminary pirt (phenomena identification and ranking table) for very high temperature gas-cooled reactors, Tech. rep., Korea Atomic Energy Research Institute (2005).

[2] H. M. McIlroy, D. M. McEligot, R. J. Pink, Measurement of turbulent flow phenomena for the lower plenum of a prismatic gascooled reactor, Nuclear Engineering and Design 240 (2) (2010) 416-428.

[3] I. A. Said, M. M. Taha, S. Usman, B. G. Woods, M. H. AlDahhan, Investigation of natural convection heat transfer in a unique scaled-down dual-channel facility, AIChE Journal 63 (1) (2017) 387-396

[4] F. I. Valentín, N. Artoun, R. Anderson, M. Kawaji, D. M. McEligot, Study of convection heat transfer in a very high temperature reactor flow channel: Numerical and experimental results, Nuclear Technology 196 (3) (2016) 661-673.

[5] C. H. Oh, E. S. Kim, Air-ingress analysis: Part 1. Theoretical approach, Nucl. Eng. Des. 241 (1) (2011) 203-212. doi:10. 1016/j.nucengdes. 2010.05 .064 .

URL http://dx.doi.org/10.1016/j.nucengdes.2010.05.064

[6] Y. Inaba, K. Sekita, T. Nemoto, Y. Honda, D. Tochio, H. Sato, S. Nakagawa, S. Takada, K. Sawa, Nuclear Heat Supply Fluctuation Tests by Non-Nuclear Heating With HTTR, Journal of Nuclear Engineering and Radiation Science 2 (4) (2016) 41001. URL http://dx.doi.org/10.1115/1.4034320

[7] R. R. Schult, P. D. Bayless, R. W. Johnson, J. R. Wolf, B. Woods, Scaling studies for high temperature test facility and modular high temperature gas-cooled reactor, Tech. rep., Idaho National Laboratory (INL) (2012).

[8] R. R. Schultz, P. D. Bayless, R. W. Johnson, W. T. Taitano, J. R. Wolf, G. E. McCreery, Studies related to the oregon state university high temperature test facility: Scaling, the validation matrix, and similarities to the modular high temperature gascooled reactor, Tech. rep., Idaho National Laboratory (INL) (2010).

[9] X. Sun, R. Christensen, C. Oh, Investigation of countercurrent helium-air flows in air-ingress accidents for vhtrs, Tech. rep., Battelle Energy ALliance, LLC (2013).

[10] D. J. Arcilesi, Developmental Analysis and Design of a Scaleddown Test Facility for a VHTR Air-ingress Accident, Ph.D. thesis, Ohio State University (2012).

[11] C. H. Oh, C. Davis, L. Siefken, R. Moore, J. Kim, G. C. Park, J. C. Lee, W. R. Martin, Development Of Safety Analysis Codes And Experimental Validation For A Very High Temperature Gas-Cooled Reactor, Tech. Rep. March, Idaho National Labratory, Idaho Falls (2006).

[12] C. H. Oh, H. S. Kang, E. S. Kim, Air-ingress analysis: Part 2-Computational fluid dynamic models, Nuclear Engineering and Design 241 (1) (2011) 213-225. doi:http://dx.doi.org/ $10.1016 / j$.nucengdes . 2010.05.065.

URL http://www.sciencedirect.com/science/article/pii/ S0029549310004127

[13] D. J. Arcilesi, T. K. Ham, I. H. Kim, X. Sun, R. N. Christensen, C. H. Oh, Scaling and design analyses of a scaleddown, high-temperature test facility for experimental investigation of the initial stages of a VHTR air-ingress accident, Nuclear Engineering and Design 288 (2015) 141-162. doi: 
$10.1016 / j$. nucengdes. 2015.03 .007$.

URL http://dx.doi.org/10.1016/j.nucengdes.2015.03.007

[14] T. K. Ham, D. J. Arcilesi, I. H. Kim, X. Sun, R. N. Christensen,

C. H. Oh, E. S. Kim, Computational fluid dynamics analysis of the initial stages of a vhtr air-ingress accident using a scaleddown model, Nuclear Engineering and Design 300 (2016) 517 529 .

[15] H. G. Jin, H. C. No, H. I. Kim, Stratified flow-induced airingress accident assessment of the gamma code in htgrs, Nuclear Engineering and Design 241 (8) (2011) 3216-3223.

[16] H. G. Jin, H. C. No, B. H. Park, Effects of the onset time of natural circulation on safety in an air ingress accident involving a htgr, Nuclear Engineering and Design 250 (2012) 626-632.

[17] S. Kim, M. S. Yadav, J. D. Talley, A. Ireland, S. M. Bajorek, Separate effects experiments for air-ingress in helium filled vessel, Experimental Thermal and Fluid Science 49 (2013) 1-13.

[18] A. Campo, M. M. Papari, E. Abu-Nada, Estimation of the minimum prandtl number for binary gas mixtures formed with light helium and certain heavier gases: Application to thermoacoustic refrigerators, Applied Thermal Engineering 31 (16) (2011) 3142-3146.

[19] J. Liu, G. Ahlers, Rayleigh-benard convection in binary-gas mixtures: Thermophysical properties and the onset of convection, Physical Review E 55 (6) (1997) 6950.

[20] M. Taylor, K. Bauer, D. McEligot, Internal forced convection to low-prandtl-number gas mixtures, International journal of heat and mass transfer 31 (1) (1988) 13-25.

[21] T. Takeda, M. Hishida, Studies on diffusion and natural convection of two-component gases, Nuclear Engineering and Design 135 (3) (1992) 341-354. doi:10.1016/0029-5493(92) 90201-6.

[22] T. Takeda, M. Hishida, Studies on molecular diffusion and natural convection of multi-component gases, Vol. 135, 1993, pp. 1489-1497.

[23] T. Takeda, M. Hishida, Studies on molecular diffusion and natural convection in a multicomponent gas system, International Journal of Heat and Mass Transfer 39 (3) (1996) 527-536. doi:10.1016/0017-9310(95)00148-3.

[24] T. Zhai, LOCA and Air Ingress Accident Analysis of a Pebble Bed Reactor, Ph.D. thesis, Massachusetts Institute of Technology (2003).

[25] A. C. Kadak, T. Zhai, Air ingress benchmarking with computational fluid dynamics analysis 236 (October 2004) (2006) 587-602. doi:10.1016/j.nucengdes.2005.11.019.

[26] C. H. Oh, E. S. Kim, H. C. No, N. Z. Cho, Final report on experimental validation of stratified flow phenomena, graphite oxidation, and mitigation strategies of air ingress accidents, Tech. rep., Idaho National Laboratory (INL) (2011).

[27] N. Kodochigov, Y. Sukharev, E. Marova, N. PonomarevStepnoy, E. Glushkov, P. Fomichenko, Neutronic features of the gt-mhr reactor, Nuclear Engineering and Design 222 (2) (2003) 161-171.

[28] J. R. Welty, C. E. Wicks, R. E. Wilson, Fundamentals of Momentum, Heat, and Mass Transfer, 3rd Edition, Wiley, New York, 1984

[29] C. R. Wilke, Diffusional properties of multicomponent gases, Chemical Engineering Progress 46 (2) (1950) 95-104. 